\title{
Myocardial diffusion tensor imaging using diffusion-prepared SSFP
}

\author{
Elizabeth M Tunnicliffe ${ }^{1,2^{*}}$, Joseph Suttie ${ }^{2}$, Rina Ariga ${ }^{2}$, Stefan Neubauer ${ }^{2}$, Matthew D Robson ${ }^{2}$ \\ From 16th Annual SCMR Scientific Sessions \\ San Francisco, CA, USA. 31 January - 3 February 2013
}

\begin{abstract}
Background
Diffusion tensor imaging of the myocardium is challenging due to the large bulk motion of the heart relative to the distance water diffuses. One solution is to use diffusion gradients on two consecutive heartbeats, with EPI to readout the stimulated echo [1]. The technique has not been widely adopted, primarily due to the long imaging times required to overcome the low SNR of the technique. Recent new technology such as 3T scanners and 32-channel cardiac arrays improve the SNR, helping to make this approach feasible clinically. SSFP provides reduced distortion and high image quality, therefore we investigated the feasibility of replacing the EPI readout with SSFP for myocardial diffusion tensor imaging at 3T.
\end{abstract}

\section{Methods}

The modified ECG-gated SSFP sequence including a diffusion preparation module is shown in Figure 1a. A final $90^{\circ}$ tip-up pulse was required to enable an SSFP readout module rather than EPI. In order to avoid signal voids due to phase accrued from sub-millimetre bulk motion between the two diffusion gradients, a dephase gradient in the slice direction was included before the tip-up pulse, with this residual phase gradient rewound during each readout [2].

The sequence was tested on a 3T Siemens Trio using a 32-channel coil. Images were acquired in diastole $(650 \mathrm{~ms}$ after the R-wave). Two heartbeats for T1 recovery were included between each imaging module, and the following readout parameters were used: $\mathrm{TR} / \mathrm{TE}=2.5 / 1.3 \mathrm{~ms}, \alpha=120^{\circ}$, bandwidth $1021 \mathrm{~Hz} / \mathrm{px}$, GRAPPA ( $\mathrm{R}=2)$, matrix size $96 \times 92$, voxel size $2.7 \times 2.7 \times 10 \mathrm{~mm}$. One $\mathrm{b}=0$ image and 3 directions with prescribed $b=300 \mathrm{~s} / \mathrm{mm}^{2}$ were acquired in each 14-heartbeat breathhold, with three averages, requiring six breathholds for a single slice. Data were analysed in
Matlab and mean diffusivity (MD), fractional anisotropy (FA) and helix angle (HA) calculated. A mid-ventricular slice was acquired in three normal volunteers and one patient with known hypertrophic cardiomyopathy (HCM).

\section{Results}

Maps of MD, FA and HA for one normal volunteer and the HCM patient are shown in Figure 1b, demonstrating that this novel technique allows the acquisition of distortion-free images at 3T, and that the diffusion tensor and derived quantities can be calculated. The MD and FA for the three volunteers and one patient are reported in Table 1. FA shows good agreement with recently reported literature values [3], but the MD is slightly higher. This is due to T1-weighting of the signal due to the recovery of non-diffusion-weighted signal during the readout, which introduces a small positive bias to the MD [4].

A large change in FA is observed in the patient with $\mathrm{HCM}$, as showed previously [5].

\section{Conclusions}

We have demonstrated the feasibility of diffusion-prepared SSFP for diffusion tensor imaging of the myocardium at $3 \mathrm{~T}$, and shown its sensitivity to the presence of myocardial disarray in HCM.

\section{Funding}

Part of this research was funded by the National Institute for Health Research (NIHR) Oxford Biomedical Research Centre based at The Oxford University Hospitals Trust at the University of Oxford. The views expressed are those of the author(s) and not necessarily those of the NHS, the NIHR or the Department of Health. We also acknowledge funding from the UK Department of Health. 
a.

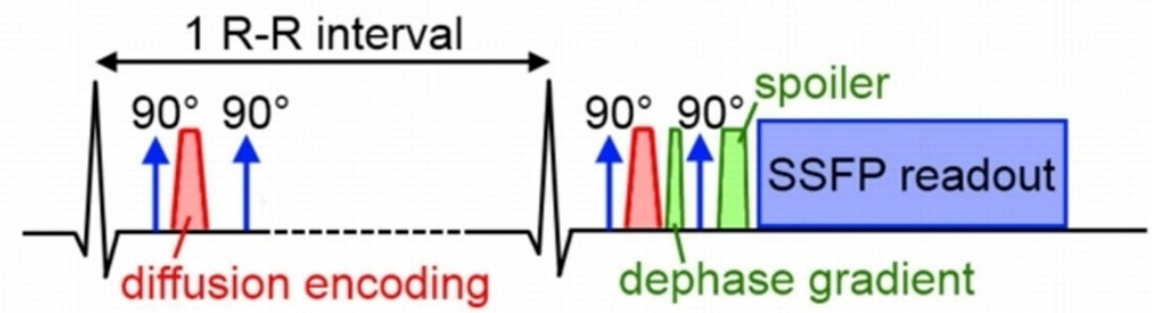

b.

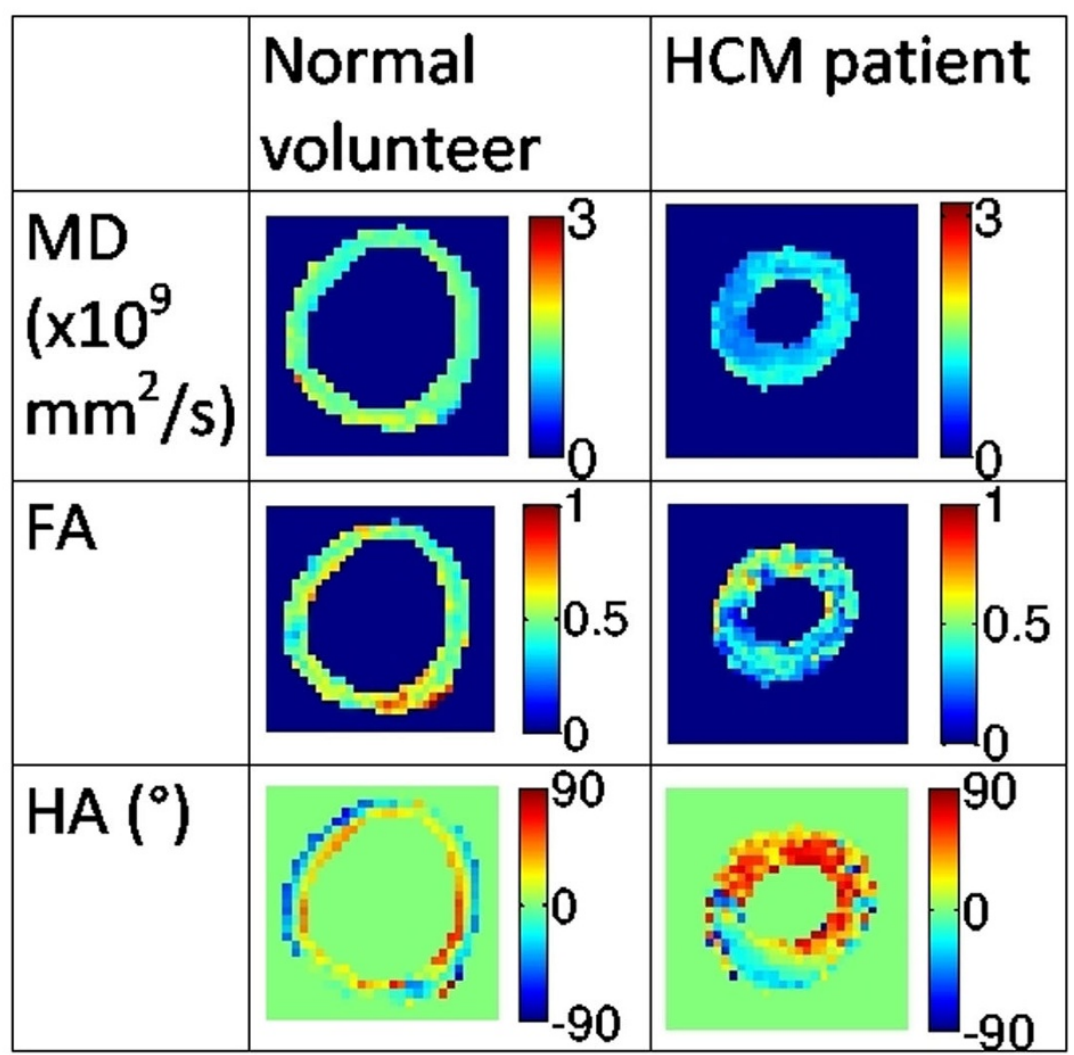

Figure 1 a. A schematic diagram of the diffusion-prepared SSFP sequence. b. Example maps from a normal volunteer and a hypertrophic cardiomyopathy patient.

Table 1 Results for mean diffusivity and fractional anisotropy for three normal volunteers and one patient with HCM.

\begin{tabular}{ccc}
\hline & $\begin{array}{c}\text { Mean diffusivity }\left(\times 10^{-6}\right. \\
\left.\mathrm{mm}^{2} / \mathrm{s}\right)\end{array}$ & $\begin{array}{c}\text { Fractional } \\
\text { anisotropy }\end{array}$ \\
\hline $\begin{array}{c}\text { Normal volunteers } \\
(\mathrm{n}=3)\end{array}$ & $1204 \pm 113$ & $0.62 \pm 0.08$ \\
HCM patient $(\mathrm{n}=1)$ & 1053 & 0.37 \\
\hline
\end{tabular}

Author details

${ }^{1}$ AVIC, Radcliffe Department of Medicine, University of Oxford, Oxford, UK ${ }^{2}$ OCMR, Radcliffe Department of Medicine, University of Oxford, Oxford, UK.

Published: 30 January 2013

\section{References}

1. Edelman, et al.. MRM 32:423.

2. Lin, et al:. MRM 60:8.

3. Nielles-Vallespin, et al.: MRM 2012, in print.

4. Jeong, et al:. MRM 50:821.

5. Tseng, et al:. JMRI 23:1. 
doi:10.1186/1532-429X-15-S1-P1

Cite this article as: Tunnicliffe et al:: Myocardial diffusion tensor imaging using diffusion-prepared SSFP. Journal of Cardiovascular Magnetic

Resonance 2013 15(Suppl 1):P1.

Submit your next manuscript to BioMed Central and take full advantage of:

- Convenient online submission

- Thorough peer review

- No space constraints or color figure charges

- Immediate publication on acceptance

- Inclusion in PubMed, CAS, Scopus and Google Scholar

- Research which is freely available for redistribution

Submit your manuscript at 